\title{
Edwardsiella ictaluri type III secretion system (T3SS) effector EseN is a phosphothreonine lyase that inactivates ERK1/2
}

\author{
Lidiya P. Dubytska ${ }^{1,3}$, Ronald L. Thune ${ }^{1,2, *}$ \\ ${ }^{1}$ Department of Pathobiological Sciences, Louisiana State University School of Veterinary Medicine, Baton Rouge, \\ Louisiana 70803, USA \\ ${ }^{2}$ School of Animal Science, Louisiana State University Agricultural Center, Baton Rouge, Louisiana 70803, USA \\ ${ }^{3}$ Present address: Department of Biology and Chemistry, Southern University and A \& M College, Baton Rouge, \\ Louisiana 70813, USA
}

\begin{abstract}
EseN is a type III secretion system (T3SS) effector that is encoded on the Edwardsiella ictaluri chromosome and is homologous to a family of T3SS effector proteins with phosphothreonine lyase (PTL) activity, including OspF from Shigella and SpvC from Salmonella. A yeast2-hybrid system was used to identify the major vault protein (MVP) as a specific host-cell binding partner for EseN, and the proximity ligation assay (PLA) confirmed the interaction. Similar to other pathogens, E. ictaluri invasion activates extracellular signal-regulated kinases 1 and 2 (ERK1/2) early in the infection, which are subsequently inactivated by EseN. Structurally, EseN contains a highly conserved docking motif that is required for specific binding to mitogen-activated protein kinases, such as ERK1/2, and a motif that is essential for PTL activity. Immunoblotting and immunofluorescence analyses indicate that EseN inactivates ERK1/2 by dephosphorylation in vivo in the head kidney of infected fish and ex vivo in head kidney derived macrophages. Interaction of EseN with phosphorylated ERK1/2 (pERK1/2) was also confirmed using PLA, suggesting that MVP serves as a signaling scaffold for ERK1/2 and EseN. Channel catfish Ictalurus punctatus infected with $E$. ictaluri strains lacking the eseN gene had reduced numbers of E. ictaluri in the tissues following infection and reduced mortality compared to fish infected with the wild-type. Our results indicate that eseN encodes a PTL domain that interacts with MVP as a possible scaffold protein and inactivates pERK1/2 to ERK1/2, resulting in increased proliferation of E. ictaluri and, ultimately, death of the host.
\end{abstract}

KEY WORDS: Edwardsiella ictaluri - Type III secretion system effectors $\cdot$ EseN $\cdot$ ERK1/2 $\cdot$ MVP protein $\cdot$ Channel catfish $\cdot$ Ictalurus punctatus

\section{INTRODUCTION}

Edwardsiella ictaluri is a Gram-negative bacterial pathogen that causes enteric septicemia of catfish (ESC), a major disease of farmed-raised channel catfish Ictalurus punctatus. Central to E. ictaluri pathogenesis is a type III secretion system (T3SS) that is homologous to the Salmonella-pathogenicity-

${ }^{*}$ Corresponding author: rthune@lsu.edu island-2 (SPI-2) T3SS (Thune et al. 2007) and is responsible for the translocation of bacterial proteins known as effectors into the host cell cytoplasm (Dubytska et al. 2016). Bacterial T3SS effectors are known for interacting with various components of host cells resulting in alterations in host cell structure and/or physiology that favor bacterial survival in the host (Miao et al. 2003, Agbor \& McCormick 
2011, Figueira \& Holden 2012, Wall \& McCormick 2014). Effects include intracellular uptake, surface colonization of the cell without uptake, adherence to macrophages and inhibition of phagocytosis, cytotoxicity, vesicular trafficking, control of programmed cell death, manipulation of gene expression, and up- and downregulation of inflammatory cytokines (Cornelis \& Van Gijsegem 2000, Galán \& Wolf-Watz 2006, Coburn et al. 2007, Agbor \& McCormick 2011, Dean 2011, Figueira \& Holden 2012, Kaur \& Jain 2012, Kline et al. 2012, Marteyn et al. 2012). A recent report provided the identification and characterization of 9 T3SS effector proteins of the E. ictaluri T3SS that are translocated from bacteria in the $E d$ wardsiella-containing vacuole (ECV) through the vacuolar membrane to the host cell cytoplasm (Dubytska et al. 2016). These effector proteins include EseN, which carries a phosphothreonine lyase (PTL) domain that is homologous to T3SS effectors in other bacterial pathogens that are involved in the inactivation of mitogen-activated protein kinases (MAPKs) (Kim et al. 2008, Zurawski et al. 2009, Haneda et al. 2012). EseN also contains a highly conserved docking motif that is required for specific binding to MAPKs (Smith et al. 2009, Neumann et al. 2014, Wall \& McCormick 2014).

MAPK pathways are central signaling cascades that are essential for activation of host innate immune responses (Zhang \& Dong 2005, Krzyzowska et al. 2010). Moreover, MAPKs can cooperate with other signal transduction pathways, including that of the transcriptional regulator nuclear factor- $\kappa \beta$ (NF- $\kappa \beta)$, which regulates transcription of genes important for cytokine and chemokine production, such as interleukin(IL)-6, IL-8, IL-12, and tumor necrosis factor $\alpha$ (Lawrence 2009, Skaug et al. 2009, Zhu \& Mohan 2010), as well as the anti-apoptotic factor Bcl-2 (Bhavsar et al. 2007, Skaug et al. 2009).

MAPKs can be classified into 3 main families: extracellular signal-regulated protein kinases 1 and 2 (ERK1/2), p38 kinases, and c-Jun N-terminal kinases (JNKs). Activation of MAPKs requires phosphorylation of both the threonine (Thr) and tyrosine (Tyr) residues within their Thr-X-Tyr activation motif in response to a broad range of extracellular and intracellular signals, including bacterial infection (Zhang \& Dong 2005, Krzyzowska et al. 2010, Arthur \& Ley 2013). Phosphorylation of MAPKs leads to activation or inhibition of transcription factors (Zhang \& Dong 2005, Krzyzowska et al. 2010, Arthur \& Ley 2013), resulting in up- or downregulation of important immune factor genes that regulate bacterial infections in the host (Arbibe et al. 2007, Kramer et al. 2007, Li et al.
2007, Zhang et al. 2007, Mazurkiewicz et al. 2008, He et al. 2015). In response, bacterial pathogens employ T3SS effectors that interact with different components of the same signaling network to subvert the host response to the infection (Miao et al. 2003, Agbor \& McCormick 2011, Figueira \& Holden 2012, Wall \& McCormick 2014).

Translocation of the T3SS effector EseN from the ECV to the cytosol of head kidney derived macrophages (HKDMs) and its role in intracellular replication was reported previously (Dubytska et al. 2016). Because EseN is important for virulence of $E$. ictaluri and the intracellular target(s) of EseN is/are unknown, a yeast-2-hybrid (Y2H) system was used to identify potential host target proteins of EseN, and the proximity ligation assay (PLA) was used to confirm the interaction. In this work, we demonstrate for the first time that the E. ictaluri ese $N$ gene encodes a protein that contains a functional PTL domain that interacts with the major vault protein (MVP), possibly as a scaffold protein, and inactivates ERK1/2, playing a major role in the pathogenesis of an E. ictaluri infection.

\section{MATERIALS AND METHODS}

\section{Bacterial strains and growth conditions}

Wild-type Edwardsiella ictaluri 93-146 (WT) was isolated from moribund channel catfish in a natural outbreak of ESC on a commercial catfish farm. The T3SS mutant 65ST carries a mini-Tn5Km insertion in the esaU gene of E. ictaluri 93-146, which encodes an integral apparatus membrane protein, EsaU, that abrogates translocation when knocked out (Thune et al. 2007). The eseN mutant ( $\Delta e s e N$ ) (Dubytska et al. 2016) carries a complete deletion of the ese $N$ gene of E. ictaluri 93-146, and the $\Delta e s e N$ complemented strain $(\Delta e s e N / e s e N)$ contains the eseN gene under control of its own promoter on the pBBR1-MCS4 complementation plasmid (Kovach et al. 1995) in the E. ictaluri $\Delta e s e N$ strain (Dubytska et al. 2016). All strains were grown in porcine brain-heart-infusion broth (BHIB; Becton Dickinson) at $28^{\circ} \mathrm{C}$ on a Cel-Gro tissue culture rotator (Lab-Line). Ampicillin was added at $200 \mu \mathrm{g} \mathrm{ml}^{-1}$ for growing E. ictaluri $\Delta$ eseN/ eseN. The number of colony forming units (CFU) was determined by making triplicate 10 -fold serial dilutions in sterile phosphate-buffered saline (PBS) and drop plating $20 \mu \mathrm{l}$ aliquots on trypticase soy agar plates supplemented with $5 \%$ de-fibrinated sheep blood (BA) for colony counting. 


\section{Y2H assay}

Messenger RNA extraction. Uninfected HKDMs cultured in $25 \mathrm{~cm}$ flasks $(\mathrm{n}=10)$ with $5-7 \times 10^{5}$ cells each were washed with PBS at $4^{\circ} \mathrm{C}$ and lysed in $15 \mathrm{ml}$ of FastTrack Lysis buffer (Thermo Fisher Scientific). The mRNA was prepared using the FastTrack MAG mRNA Isolation kit according to the manufacturer's instructions (Thermo Fisher Scientific).

Creating the cDNA library. A 3-frame channel catfish HKDM cDNA prey library was created in the pDONR222 vector using the CloneMiner II cDNA Library construction kit according to the manufacturer's instructions (Invitrogen). To reduce 5'-untranslated regions from the mRNA that may contain stop codons, cDNA was fractionated by column chromatography to obtain insert sizes in the range of $0.2-2.8 \mathrm{~kb}$. The titer for each frame was $1-3 \times 10^{7} \mathrm{CFU} \mathrm{ml}^{-1}$. Each frame was also checked for quality by digesting the insert of 24 plasmid DNA preps and sequencing with the attL1 primer of the pDONR222 plasmid.

Screening of the prey library. The ProQuest TwoHybrid System (Invitrogen) was employed to identify the specific protein binding partner for T3SS effector EseN. The HKDM cDNA library was transferred from pDONR222 to pDEST22. The Y2H system uses the chromosomal DNA binding domain that serves as the upstream activating sequence (UAS) for the yeast GAL4 protein and depends on the fact that transcription initiation factors are comprised of 2 domains, a DNA binding domain (BD) and an activation domain (AD). Basically, EseN fused in frame to the GAL4 BD was constructed on pDEST32 to serve as the bait, while the cDNA fusions to GAL4 AD were constructed on pDEST22 to serve as the prey library. The bait and prey plasmids were then transformed into Saccharomyces cerevisiae strain MaV203, which contains single copies of 3 reporter genes (HIS3, $U R A 3$, and lacZ) that are stably integrated at different loci in the yeast genome. The promoter regions of the 3 reporter genes each contain the UAS for GAL4. The GAL4 BD/EseN fusion protein binds to the GAL4 UAS, and if EseN interacts with a protein in the GAL4 AD cDNA prey library, the GAL4 AD is brought together with the GAL4 BD through the interaction of the 2 proteins. The reporter genes are not expressed unless a protein that interacts with EseN binds and brings the GAL4 AD in position to bind RNA polymerase, resulting in transcriptional activation of the reporter gene located downstream from the UAS. Positive interactions were initially detected by selection on plates lacking histidine so that only cells producing histidine from an activated
HIS3 can grow. S. cerevisiae strain MAV203 harboring pDEST32-EseN and prey plasmid only, as well as 2 independent clones of pDEST32-EseN and pDEST22 with non-specific cDNA were used as negative controls. Positive clones and negative controls were then replica plated to plates lacking uracil so that only cells producing uracil from an activated URA3 can grow, further indicating a positive protein-protein interaction. Varying concentrations of the HIS 3 inhibitor 3-amino-1,2,4-triazole (3AT) were also used to evaluate the strength of the HIS3 activation, with growth in 3AT indicating stronger interaction. In addition, 5-fluoroorotic acid (5FOA) was used to further test induction of $U R A 3$, which would result in the conversion of 5FOA to 5-fluorouracil, which is toxic to yeast expressing $U R A 3$, resulting in suppression of growth.

Plasmid DNA from positive clones was isolated and transformed into One-Shot TOP-10 Chemically Competent Escherichia coli according to the manufacturer's instructions (Invitrogen). To confirm the interaction of the EseN bait and the isolated prey in an independent assay, plasmid DNA from 3-5 positive colonies of each transformant was used to perform the quantitative $\beta$-galactosidase ( $\beta$-gal) assay, using both o-nitrophenyl- $\beta$-D-galactopyranoside (ONPG) and the more sensitive chlorophenol red- $\beta$-D-galactopyranoside (CPRG) as substrates. Stronger $\beta$-gal activity means a stronger protein-protein interaction. In addition, the same prey plasmid was used to repeat the $\mathrm{Y} 2 \mathrm{H}$ assay with the EseN bait and for sequence analyses of the prey insert.

\section{Proximity ligation assay}

Production and purification of recombinant EseN. To construct a plasmid expressing recombinant EseN, the eseN gene was PCR amplified from E. ictaluri WT genomic DNA using oligonucleotide primers eseN/ pET26bF (5'-GAA TTA ATT CGG $\underline{\text { ATC }} \underline{\text { CGA TGA }}$ ATG AGA GCC TGA AAA ATA ATT TCG ACA CTC-3') and eseN/pET26bR (5'-GCC GC $\underline{A} \underline{\text { AGC }}$ TTC TCT GTC ATT AAA CGA TAA AAC GGC TCC TCT CGT AAT GCT TG-3') with added BamHI and HindIII restriction sites underlined, respectively. The PCR product was cloned into the pET26b (+) expression vector (Novagen) and fused in-frame to a sequence encoding a $6 \times$ His purification tag at the carboxy terminus of the EseN protein. The resulting ligation mix was transformed into E. coli NovaBlue Competent Cells (Novagen) and selected on LuriaBertani (LB) agar with $50 \mu \mathrm{g} \mathrm{ml}^{-1}$ kanamycin at $37^{\circ} \mathrm{C}$. 
The cloned eseN::6his sequence was verified by DNA sequencing. The verified plasmid was transformed into the E. coli expression strain BL21 ( $\lambda \mathrm{DE} 3$ ), and transformants were selected on LB agar with $50 \mu \mathrm{g}$ $\mathrm{ml}^{-1}$ of kanamycin at $37^{\circ} \mathrm{C}$. Production of EseN was induced in BHIB broth at an optical density of 0.5 at $600 \mathrm{~nm}$ by adding $1 \mathrm{mM}$ isopropyl $\beta$-D-1-thiogalactopyranoside and incubating for $3 \mathrm{~h}$. Cells were harvested, re-suspended in PBS with $6 \mathrm{M}$ guanidine, disrupted using a Model 500 Sonic Dismembrator (Fisher Scientific) at an amplitude setting of $35 \%$ for $10 \mathrm{~s}$ on/10 s off for $10 \mathrm{~min}$, and centrifuged at 20000 $\times g$ for 30 min to pellet the cell debris. EseN was purified from the supernatant using the HisPur Cobalt Purification kit according to the manufacturer's instructions (Thermo Fisher Scientific). The purity and size of the eluted EseN protein was analyzed by SDSPAGE, and its identity was confirmed by mass spectrometry in the Louisiana State University Mass Spectrometry Facility.

Anti-EseN antibody preparation and cellular localization of EseN. The EseN antibody was produced in a goat by injecting $1 \mathrm{ml}$ of $1 \mathrm{mg} \mathrm{ml}^{-1}$ purified EseN into each hind quadriceps 5 times at 2 wk intervals. The titer of anti-EseN in the serum was determined by dot blot ELISA using purified EseN. To eliminate antibody that is cross-reactive with other E. ictaluri proteins, the serum was pre-absorbed against total protein extracted from E. ictaluri $\Delta e s e N$ and then affinity purified using Magne Protein G Beads for antibody purification according to the manufacturer's instructions (Promega). Specificity of anti-EseN antibody was confirmed by Western blotting and by comparative immunofluorescence using HKDMs infected with WT or $\Delta e s e N$ E. ictaluri.

Specific PLA interaction of MVP and ERK1/2. Initial intracellular localization of EseN in E. ictaluri-infected HKDMs used the goat anti-EseN as the primary antibody and FITC-labeled donkey anti-goat immunoglobulin as the secondary. Interactions between EseN and MVP were confirmed by using the Duolink PLA kit according to the manufacturer's instructions (SigmaAldrich). The goat anti-EseN and rabbit monoclonal anti-MVP (Abcam) were used as primary antibodies, and anti-rabbit and anti-goat PLA probes were used as secondary antibodies. Sites of protein-protein interaction were detected as red fluorescent spots on an Olympus Fluoview FV10i confocal microscope using Texas Red filters for PLA fluorophore detection and a DAPI filter to visualize the nuclei.

Specific PLA interaction of EseN and pERK1/2. Although ERK1/2 was not detected as interacting with EseN in the $\mathrm{Y} 2 \mathrm{H}$ assay, dephosphorylation of activated pERK1/2 to inactive ERK1/2 by EseN suggests that a protein-protein interaction occurred. Consequently, a PLA was conducted using the goat EseN antibody and rabbit polyclonal anti-pERK1/2 (Cell Signaling Technology) as the primary antibodies. The assay and image detection were as above.

\section{ERK1/2 activity assays}

ERK1/2 activation by E. ictaluri. ERK1/2 activation by $E$. ictaluri was measured in HKDMs prepared as described by Booth et al. (2006). Briefly, HKDMs were seeded in 6-well plates and infected with a multiplicity of infection of 10-20 bacteria per HKDM of either WT or $\Delta$ eseN strains of E. ictaluri for $0.5,1.5,3$, or $5 \mathrm{~h}$. Uninfected cells were used as negative controls. At each time point, cells were washed with PBS and solubilized with $200 \mu \mathrm{l} \mathrm{well}{ }^{-1}$ of RIPA cell lysis buffer (Cell Signaling Technology) supplemented with PMSF protease inhibitor (Thermo Fisher), PhosSTOP (Sigma-Aldrich), and 5\% SDS. The $400 \mu \mathrm{l} \mathrm{sam-}$ ples were concentrated to $50 \mu \mathrm{l}$ using a $0.5 \mathrm{ml}$ Pierce Concentrator PES with a $10 \mathrm{kDa}$ molecular weight cutoff (Thermo Fisher). Protein concentrations were determined using the Bio-Rad Protein Assay (Bio-Rad Laboratories), and samples were mixed with $1 \times$ loading buffer, boiled for $5 \mathrm{~min}$, and separated on a NuPAGE Novex 4-12\% Bis-Tris Gel (Invitrogen). Gels were transferred to a PVDF membrane using PVDF iBlot Gel Transfer Stacks (Invitrogen) and an i-Blot dry blotting system (Invitrogen). Proteins were analyzed by immunoblotting with rabbit polyclonal antiERK1/2 or anti-pERK1/2 antibodies (Cell Signaling Technology). Goat anti-rabbit IRDye 800CW (LI-COR Biosciences) was used as a secondary antibody. Protein expression levels were determined by densitometry analysis of immunoblots using a LI-COR Odyssey CLx Imaging System (LI-COR Biosciences). Rabbit polyclonal anti- $\alpha / \beta$ tubulin antibody (Cell Signaling Technology) was used as a loading control, and levels of activated pERK1/2 were normalized using density values for inactive ERK1/2 and tubulin.

Ex vivo dephosphorylation assay. To evaluate subsequent dephosphorylation and inactivation of pERK1/2 by EseN, HKDMs were harvested and infected with WT, $\Delta e s e N$, or the $\Delta e s e N / e s e N$ complemented strains of E. ictaluri. The ERK1/2 pathway was activated after $6 \mathrm{~h}$ with the addition of $1 \mu \mathrm{g} \mathrm{ml}^{-1}$ of phorbol-12-myristate 13-acetate (PMA) for $15 \mathrm{~min}$. Uninfected, PMA-untreated cells served as negative controls, while uninfected, PMA-treated cells served as positive controls. After PMA treatment, cells were 
washed with PBS, fixed in $100 \%$ methanol for 10 min at $-20^{\circ} \mathrm{C}$, and blocked for $1 \mathrm{~h}$ in $1 \%$ BSA with $0.1 \mathrm{M}$ glycine in PBS at room temperature. Cells were then incubated with rabbit anti-pERK1/2 and mouse monoclonal anti-E. ictaluri in PBS with $1 \%$ BSA overnight at $4{ }^{\circ} \mathrm{C}$. Goat anti-rabbit Alexa Fluor 660 and goat anti-mouse FITC were used for pERK1/2 and $E$. ictaluri visualization, respectively. Nuclei were stained blue with DAPI.

To further evaluate dephosphorylation and inactivation of $\mathrm{pERK} 1 / 2$ by EseN, HKDMs were harvested, infected, and treated with PMA as above. After PMA treatment, however, cell lysates were produced, separated on a PAGE gel, transferred to PVDF, and analyzed by immunoblotting as described in the ERK1/2 activity assay above.

In vivo dephosphorylation assay. To evaluate the ability of E. ictaluri strains to dephosphorylate pERK1/2 in vivo in the head kidney, samples of head kidney from fish infected with WT or $\Delta e s e N E$. ictaluri were taken $3 \mathrm{~d}$ post-infection. The samples were weighed and homogenized in RIPA buffer (Cell Signaling Technology) supplemented with PMSF protease inhibitor (Thermo Fisher Scientific), PhosSTOP (SigmaAldrich), and $5 \%$ SDS. Equal protein concentrations were mixed with $1 \times$ loading buffer, boiled for $5 \mathrm{~min}$, separated on a PAGE gel, and transferred to PVDF. Cell lysates were probed using rabbit polyclonal antiERK1/2 and anti-pERK1/2. LI-COR goat anti-rabbit IRDye800CW was used as the secondary antibody and pERK1/2 bands were quantified using a LI-COR Odyssey imaging system and normalized to ERK1/2 and tubulin. Rabbit polyclonal anti-tubulin was used as a loading control.

\section{In vivo virulence evaluation of $\Delta \mathrm{eseN}$}

Specific pathogen free catfish. To establish a source of E. ictaluri-free catfish, eggs were obtained from a source with no history of ESC, separated from the egg matrix with sodium sulfite (Isaac \& Fries 1991), disinfected with iodine, hatched, and reared in the laboratory as previously described (Baumgartner et al. 2014).

Invasion and tissue persistence. To evaluate the ability of $E$. ictaluri strains to invade and replicate in the channel catfish head kidney, $20 \mathrm{l}$ tanks receiving $0.51 \mathrm{~min}^{-1}$ of de-chlorinated Baton Rouge city water were stocked with 25 fish each, and quadruplicate tanks of each treatment were challenged by immersion for $30 \mathrm{~min}$ with either BHIB (control), WT, $\Delta e s e N$, or 65ST E. ictaluri strains at final concentra- tions of $2.5 \times 10^{8} \mathrm{CFU} \mathrm{ml}{ }^{-1}$ for WT, $3.0 \times 10^{8} \mathrm{CFU} \mathrm{ml}^{-1}$ for $\Delta e s e N$, and $3.0 \times 10^{8} \mathrm{CFU} \mathrm{m}^{-1}$ for $65 \mathrm{ST}$. A single fish from each replicate tank was removed and euthanized in $1 \mathrm{~g} \mathrm{l}^{-1}$ of tricaine methanesulfonate (MS222) at $8 \mathrm{~h}$ post-infection and then daily for $5 \mathrm{~d}$. To evaluate the number of CFU per $g$ of tissue, approximately $100 \mathrm{mg}$ of head kidney tissue was removed, weighed, homogenized in $100 \mu \mathrm{l}$ of PBS, spread on BA plates, and incubated at $28^{\circ} \mathrm{C}$ for $48 \mathrm{~h}$. Colonies were counted, and the number of $\mathrm{CFU}$ recovered per $\mathrm{g}$ of tissue was determined.

Channel catfish infection challenges. Twenty-liter tanks as described above were stocked with 25 fish tank $^{-1}$. Water flow to the tanks was interrupted and fish in quadruplicate tanks were challenged by immersion with each E. ictaluri strain at a final concentration of $1.3 \times 10^{8} \mathrm{CFU} \mathrm{ml}^{-1}$ for WT, $8.4 \times 10^{7} \mathrm{CFU}$ $\mathrm{ml}^{-1}$ for $\Delta$ eseN and $9.8 \times 10^{7} \mathrm{CFU} \mathrm{m}{ }^{-1}$ for $\Delta e s e N /$ eseN. Fish exposed only to BHIB served as negative controls. After a $1 \mathrm{~h}$ exposure, water flow was restored, and the challenge dose was slowly replaced with fresh water. Dead fish were collected daily, and the presence of E. ictaluri was confirmed by streaking liver tissue from each mortality onto BA plates. Sampling continued until $3 \mathrm{~d}$ passed without a death in any treatment.

\section{Statistical analyses}

Statistical analysis of the data for the relative $\beta$-gal activity of the clones identified in the $\mathrm{Y} 2 \mathrm{H}$ screen, the pERK12/ERK1/2 conversion data, and the mortality data was conducted by using 1-way analysis of variance (ANOVA) followed by Tukey's post hoc test for pairwise comparisons. Persistence of the WT and mutant strains in the tissue following immersion exposure was analyzed by using 2-way ANOVA followed by Bonferroni's post hoc test to determine the significance of the data for the mutants compared to the WT. Percent mortality data were analyzed following an arc-sin transformation of the percentage values. All statistical computations were performed with GraphPad Prism 5.02 software (GraphPad Software).

\section{RESULTS}

\section{EseN PTL motif is homologous to other T3SS effectors}

Comparison of the amino acid (AA) sequence of EseN with that of other proteins present in the avail- 
able databases revealed significant sequence similarity to the OspF family of secreted effector proteins that carry a motif that is essential for PTL activity (Li et al. 2007, Zhu et al. 2007, Dean 2011). The PTL domain of the OspF family consists of 6 AA residues from roughly AA 102-107, GDKFHI, and 12 residues from AA 129-140, DSP(V/I)DKWK(V/I)IDM. The Edwardsiella ictaluri sequence is $100 \%$ conserved for the first sequence and $92-100 \%$ conserved for the second, depending on the pathogen in question, varying only in the V/I residues at AA 102 and 107 that are also variable in the PTL domain of the other pathogens. EseN also contains a highly conserved docking motif from AA 1-14 that is required for specific binding to MAPKs (Li et al. 2007, Zhu et al. 2007, Dean 2011). The E. ictaluri motif has identity for only 4 of the 14 AA residues, although the other 10 residues generally have differences of only 2-3 AAs among the 7 bacterial pathogens examined. The variation, however, suggests differential docking sequences for the different effector/MAPK combinations.

\section{EseN interacts with MVP}

The interaction of EseN and the HKDM cDNA prey library proteins on medium lacking histidine in the
Table 1. Confirmation of specific yeast 2-hybrid interactions between Edwardsiella ictaluri type III secretion system effector EseN and 5 individual cDNA clones encoding the major vault protein (MVP) from the prey library by detection of expression of the auxotrophic reporter genes, HIS3 or URA3. Lack of inhibition of HIS3 in the presence of 10 and $50 \mathrm{mM}$ concentrations of the specific inhibitor 3-amino1,2,4-triazole (3AT) further confirms strong activation. Failure to grow in the presence of $0.2 \% 5$-fluoroorotic acid (5FOA) indicates induction of HIS3 and production of toxic 5-fluorouracil. (+++) excellent growth; $(+)$ weak growth; $(-)$ no growth

\begin{tabular}{|c|c|c|c|c|c|c|}
\hline \multirow[t]{3}{*}{ Bait } & \multirow[t]{3}{*}{ Prey } & \multirow[t]{3}{*}{ Clone } & \multicolumn{2}{|c|}{ HIS3 induction } & \multicolumn{2}{|c|}{ URA3 induction } \\
\hline & & & $+10 \mathrm{mM}$ & $+50 \mathrm{mM}$ & No & $+0.2 \%$ \\
\hline & & & 3AT & 3AT & $5 \mathrm{FOA}$ & $5 \mathrm{FOA}$ \\
\hline \multirow[t]{5}{*}{ EseN } & MVP & 1 & +++ & +++ & +++ & - \\
\hline & & 2 & +++ & +++ & +++ & - \\
\hline & & 3 & +++ & +++ & +++ & - \\
\hline & & 4 & +++ & +++ & +++ & - \\
\hline & & 5 & +++ & +++ & +++ & - \\
\hline EseN & Empty prey & & + & - & - & + \\
\hline
\end{tabular}

$\mathrm{Y} 2 \mathrm{H}$ assay resulted in the identification of 5 clones that were then re-screened on medium lacking histidine with different concentrations of 3AT. 3AT is a competitive inhibitor of the reporter HIS3 gene that detects clones with different levels of HIS3 activity, which indicates the strength of the interaction between the bait and the prey. As indicated in Table 1, all clones grew on media without histidine, as well as on media without histidine with 10 and $50 \mathrm{mM} 3 \mathrm{AT}$ added, indicating a strong interaction between EseN and MVP. All His ${ }^{+}$clones were also URA3 positive and sensitive to $0.2 \% 5 \mathrm{FOA}$, a toxic analog of uracil. All 5 clones produced significant levels of $\beta$-gal in the ONPG and CPRG assays but with significantly differ-

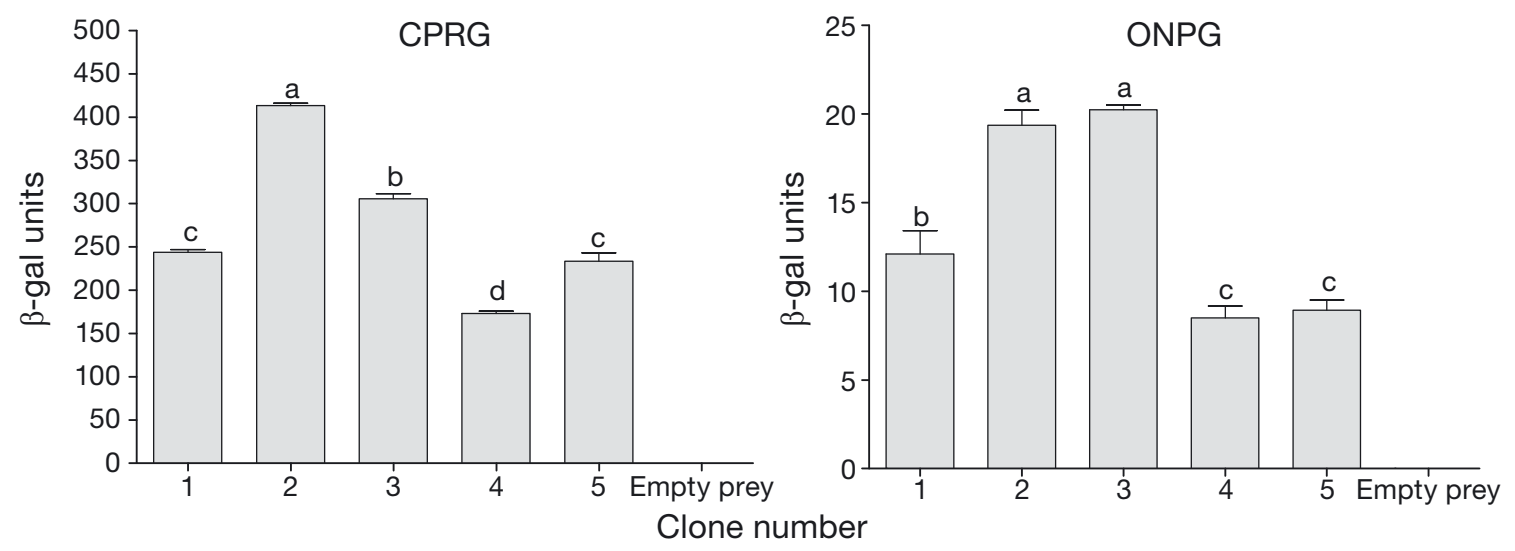

Fig. 1. Quantitative assays for $\beta$-galactosidase ( $\beta$-gal) activity for 5 individual yeast 2-hybrid clones in liquid culture using chlorophenol red- $\beta$-D-galactopyranoside (CPRG) or o-nitrophenyl- $\beta$-D-galactopyranoside (ONPG) as substrates. As a substrate, CPRG is more sensitive and the reaction time is faster than ONPG, but the strength of the reaction indicates the relative strength of the bait/prey interaction in both cases. Statistical analysis was conducted using 1-way ANOVA followed by Tukey's post hoc test for pairwise comparisons. Data are mean \pm SD of 4 replicates; clones with the same letters are not significantly different $(\mathrm{p}<0.05)$ 
ent levels of strength (Fig. 1). In addition, BLAST analyses of the sequenced pDEST32-MVP inserts indicated that all clones contained sequence for MVP, but that the length of the mvp sequences was different in different clones.

The use of the empty pDest22 vector as a negative control to measure background expression of reporter gene activity yielded little or no reporter gene activation (Table 1). Additionally, re-transformants of Saccharomyces cerevisiae strain MaV203 with pDest32EseN and pDest22-MVP were all positive for the $\mathrm{Y} 2 \mathrm{H}$ reporter genes, and the level of ONPG/CPRG activity confirmed the EseN-MVP interaction.
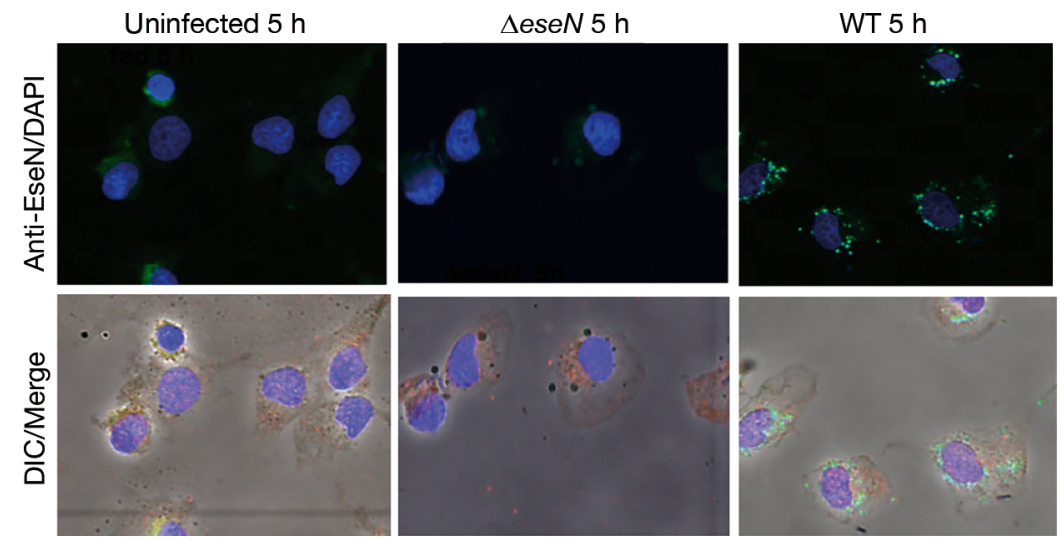

Fig. 2. Cytoplasmic localization of EseN in channel catfish head kidney derived macrophages (HKDMs) infected for $5 \mathrm{~h}$ with the Edwardsiella ictaluri wild-type (WT) or mutant eseN strains $(\Delta e s e N)$. EseN stained green only in the WT-infected HKDMs. Nuclei stained with DAPI (blue). DIC: differential interference contrast

\section{Cellular localization of EseN and co-localization of EseN with MVP}

After initial localization of EseN to the cytoplasm at $5 \mathrm{~h}$ post-infection (Fig. 2), the interaction between MVP and EseN was confirmed ex vivo using PLA. As indicated in Fig. 3, there was no red fluorescence to indicate protein-protein interaction in noninfected HKDMs, or in HKDMs infected with $\Delta e s e N$ or the T3SS mutant, 65ST. In HKDMs infected with
WT, however, the positive red fluorescent interaction signal between EseN and MVP was present, confirming the specific interaction between EseN and MVP. Subsequently, because Listeria monocytogenes is able to cover its surface with MVP via the internalin InlK to escape autophagy recognition (Dortet et al. 2012), we investigated whether MVP plays a similar role and co-localizes with E. ictaluri. Results indicate that MVP does not co-localize with E. ictaluri.
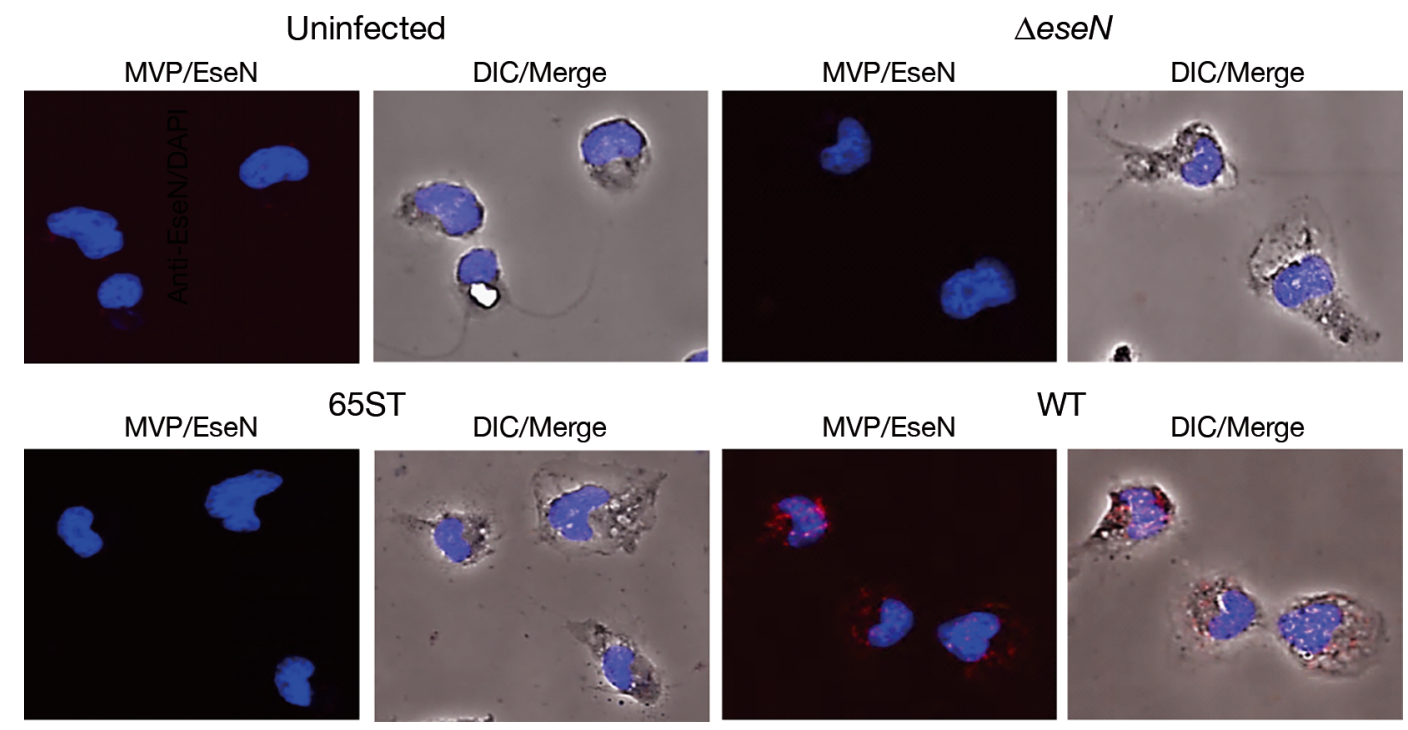

WIC/Merge

Fig. 3. Interaction between the major vault protein (MVP) and Edwardsiella ictaluri type III secretion system effector EseN in channel catfish head kidney derived macrophages (HKDMs) using the proximity ligation assay (PLA) with goat antibody to EseN and rabbit monoclonal antibody to MVP as the primary antibodies. Interactions were detected using anti-goat and antirabbit PLA probes as the secondary antibodies. Positive interactions of the PLA probes are represented by red fluorescent dots and are only present in HKDMs infected with wild-type (WT) E. ictaluri, not in the E. ictaluri T3SS knockout (65ST) or eseN mutant $(\Delta e s e N)$ strains. Nuclei stained with DAPI (blue). DIC: differential interference contrast 

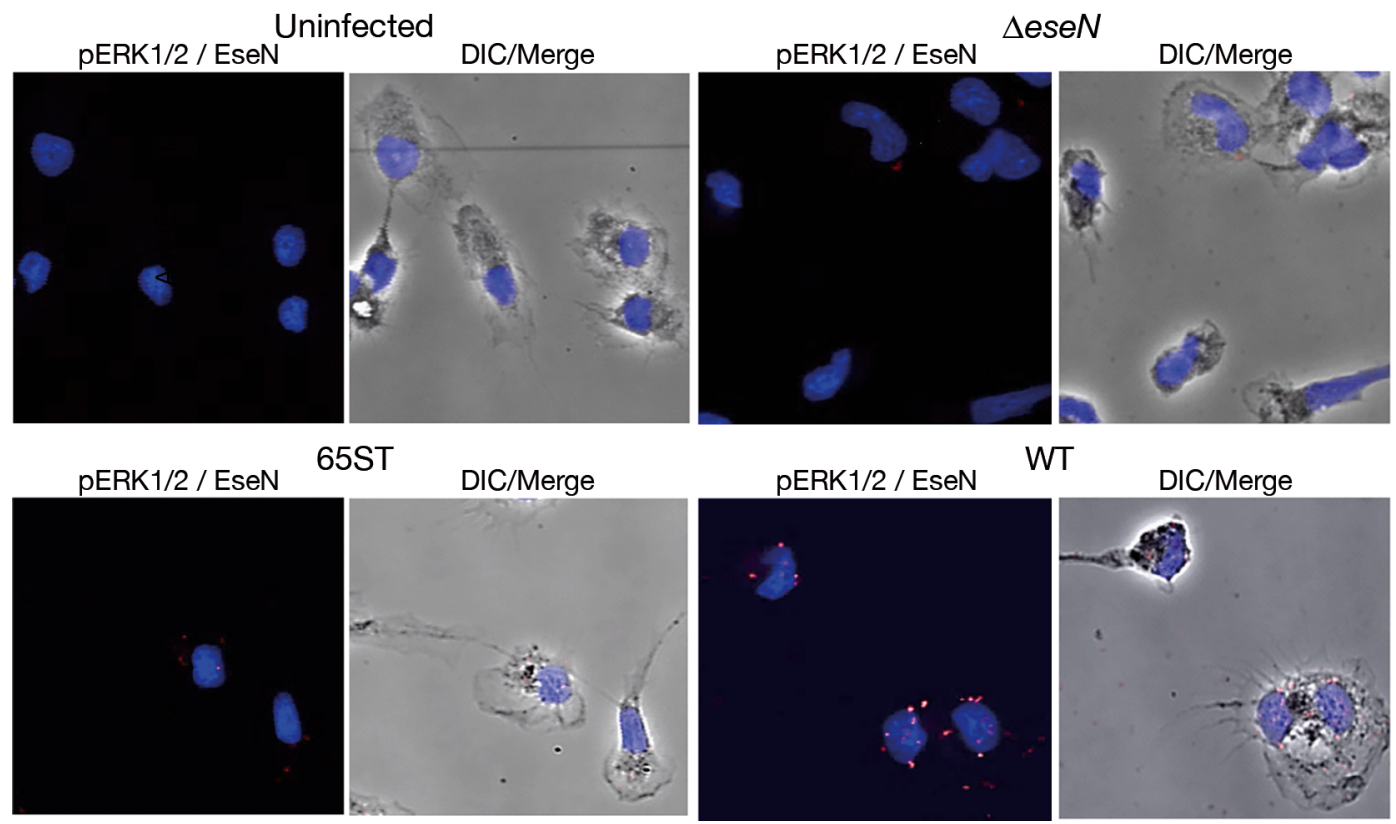

Fig. 4. Interaction between phosphorylated extracellular signal-regulated kinases 1 and 2 (pERK1/2) and EseN detected in channel catfish head kidney derived macrophages (HKDMs) by the proximity ligation assay (PLA) after $3 \mathrm{~h}$ post-infection using goat anti-EseN and rabbit polyclonal pERK1/2 as primary antibodies with anti-goat and anti-rabbit PLA probes as secondary antibodies. Positive interaction of the probes are represented by fluorescent red dots and are only present in HKDMs infected with wild-type (WT) Edwardsiella ictaluri, not in E. ictaluri type III secretion system knockout (65ST) or eseN mutant $(\Delta e s e N)$ strains. Nuclei stained with DAPI (blue). DIC: differential interference contrast

\section{EseN interacts with pERK1/2}

Interaction between EseN and pERK1/2 was also detected by PLA in HKDMs infected with WT E. ictaluri (Fig. 4), but not in uninfected HKDMs, HKDMs infected with the $\Delta e s e N$ mutant, or the T3SS mutant, 65ST. These data indicate a specific interaction between EseN and pERK1/2.

\section{E. ictaluri infection of HKDMs activates ERK1/2 early in the infection}

ERK1/2 were phosphorylated and activated in response to an E. ictaluri infection as indicated by the percentage of ERK1/2 converted to pERK1/2 (Fig. 5). This activation was present in both WT E. ictaluri and the $\Delta$ eseNmutant, indicating that activation of ERK1/2 is a response to bacterial uptake and is not EseN dependent. The ERK1/2 activation by E. ictaluri strains was detected as early as $30 \mathrm{~min}$ post-infection, but decreased at $1.5 \mathrm{~h}$ post-infection.

\section{EseN dephosphorylates pERK1/2 ex vivo}

In PMA-stimulated HKDMs, red fluorescent staining for activated pERK1/2 was observed in unin- fected cells and in cells infected with $\Delta e s e N$. Staining was reduced in the WT or in E. ictaluri $\Delta e s e N / e s e N$, indicating that levels of $\mathrm{pERK} 1 / 2$ were significantly lower (Fig. 6). Western blot analysis of PMA-stimulated HKDM lysates confirmed significantly reduced levels of pERK1/2 in WT and $\Delta$ eseN/eseN compared to uninfected cells and cells infected with $\Delta e s e N$ (Fig. 7A). These results show that EseN is required for $\mathrm{pERK} 1 / 2$ inactivation to ERK1/2 by E. ictaluri.

\section{EseN dephosphorylates pERK1/2 in vivo}

Consistent with the ex vivo results described above, a significant increase in pERK1/2 levels was detected in head kidneys infected with E. ictaluri $\Delta e s e N$, but levels of pERK1/2 in head kidneys infected with WT or $\Delta e s e N / e s e N$ E. ictaluri were not significantly different from uninfected cells (Fig. 7B). This indicates that $\mathrm{pERK} 1 / 2$ produced following a natural infection with either WT or $\Delta e s e N / e s e N E$. ictaluri was inactivated by EseN, the same as it was in HKDMs.

\section{EseN plays an important role in virulence}

Following immersion challenge, no significant difference was found between the numbers of $\mathrm{CFU} \mathrm{g}^{-1}$ 
A

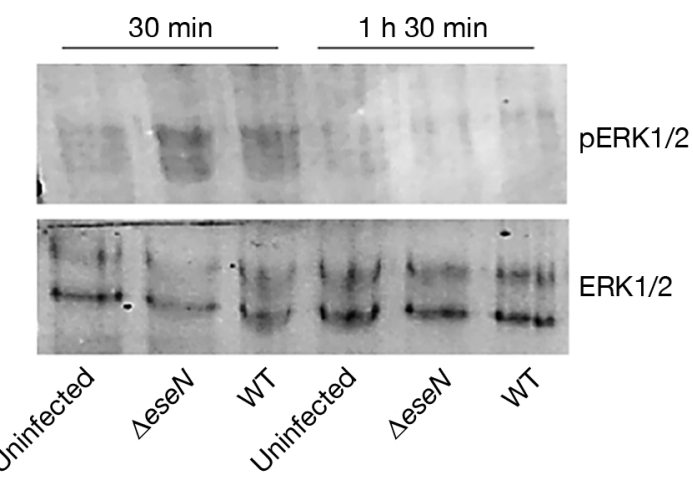

B

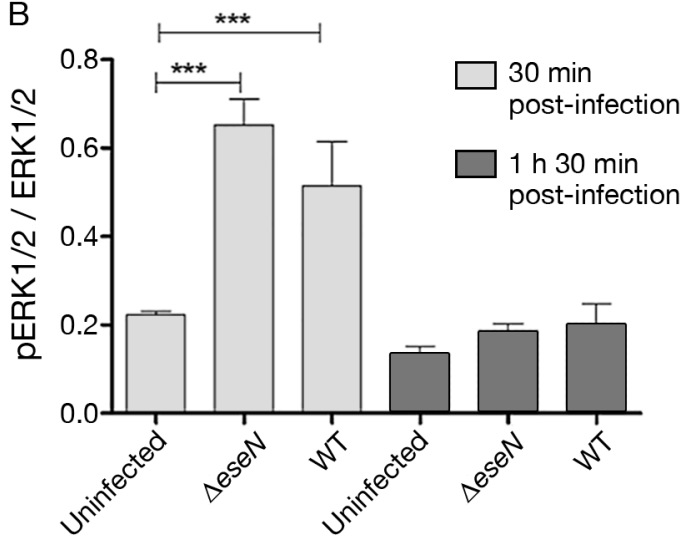

Fig. 5. (A) Extracellular signal-regulated kinases 1 and 2 (ERK1/2) are activated to phosphorylated ERK1/2 (pERK1/2) during infection of channel catfish head kidney derived macrophages by wild-type (WT) or eseN mutant $(\Delta e s e N)$ strains of Edwardsiella ictaluri. Maximum activation detected at $30 \mathrm{~min}$ post-infection was not significantly different between the WT and $\Delta e-$ seN strains, indicating no role for EseN in activation of ERK1/2. (B) Levels of pERK1/2 as detected in (A), but quantified using a LI-COR Odessey CLx imaging system (LI-COR Biosciences), with pERK1/2 bands normalized to ERK1/2 and tubulin. Activation was not dependent on the presence of EseN. Statistical analysis was conducted using 1-way ANOVA followed by Tukey's post hoc test for pairwise comparisons. Mean $\pm \operatorname{SD}\left({ }^{* * *} \mathrm{p}<0.001\right)$
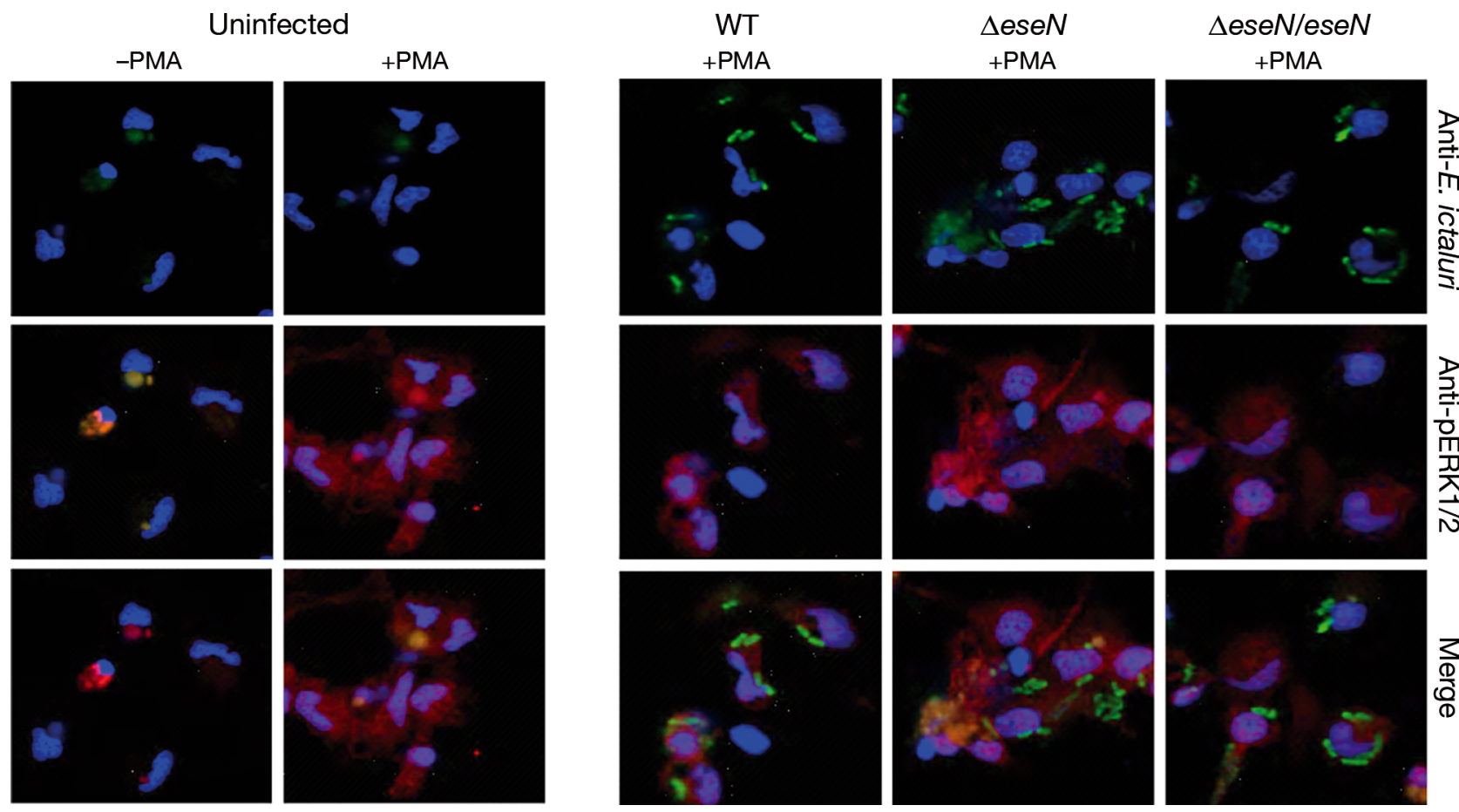

Fig. 6. Following initial phosphorylation of extracellular signal-regulated kinases 1 and 2 (ERK1/2) to the activated phosphorylated ERK1/2 (pERK1/2) by bacterial uptake as shown in Fig. 5, translocated EseN acts to de-phosphorylate and inactivate pERK1/2. Channel catfish head kidney derived macrophages were infected for $6 \mathrm{~h}$ with the wild-type Edwardsiella ictaluri (WT), an eseN mutant ( $\Delta e s e N)$, or complemented $\Delta e s e N(\Delta e s e N / e s e N)$. pERK1/2 was only identified in $\Delta e s e N$-infected cells activated with PMA, indicating de-phosphorylation of pERK1/2 by both the WT and complemented mutant E. ictaluri strains. Nuclei were stained with DAPI (blue)

tissue after $8 \mathrm{~h}$ or on Days 1 and 2. Numbers of the 65ST T3SS mutant were significantly lower than WT and $\Delta e s e N$ on Days 3 and 4 , but $\Delta e s e N$ was not significantly lower than WT until Day 5 (Fig. 8), indicating a role for other effectors. As indicated in Fig. 9,
$\Delta e s e N$ is significantly attenuated compared to the WT strain, and complementation of the eseN mutation with $\Delta$ eseN/eseN significantly restored virulence to that of the WT. The T3SS knockout mutant $65 \mathrm{ST}$, however, was previously shown to be com- 

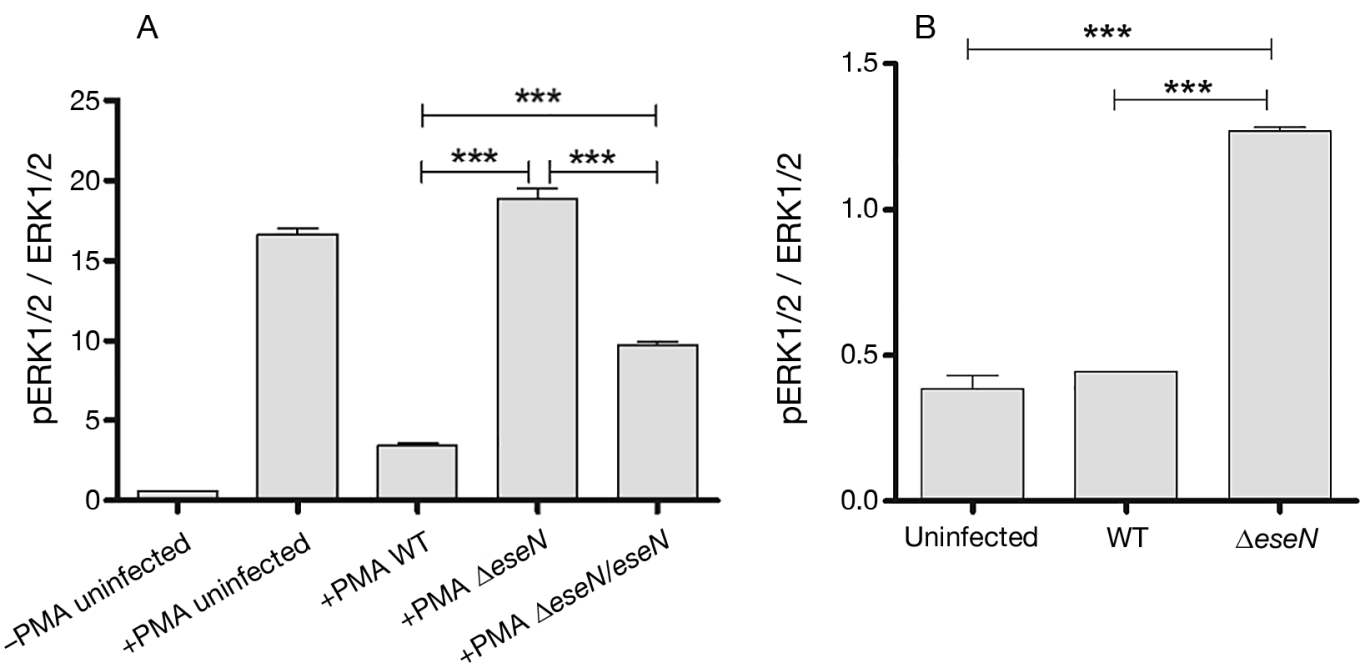

Fig. 7. Western blot results. (A) phosphorylated extracellular signal-regulated kinases 1 and 2 (pERK1/2) ex vivo in channel catfish head kidney derived macrophages infected with wild-type Edwardsiella ictaluri (WT), mutant eseN ( $\Delta e s e N)$, or the $\Delta e s e N$ complemented strain ( $\Delta$ eseN/eseN) following stimulation with phorbol-12-myristate 13-acetate (PMA) for 15 min. Both WT and the $\Delta$ eseN/eseN complemented strain inactivated pERK1/2 ex vivo. (B) pERK1/2 in vivo in catfish head kidney infected with E. ictaluri WT, $\Delta e s e N$, or $\Delta e s e N / e s e N$ conducted as described above showing that both WT and the $\Delta e s e N / e s e N$ complemented strain de-phosphorylated pERK1/2 in vivo. Comparisons between groups were based on 1-way ANOVA with the

Dunnett post hoc procedure for comparison of group means. Mean $\pm \mathrm{SD}\left({ }^{* * *} \mathrm{p}<0.001\right)$

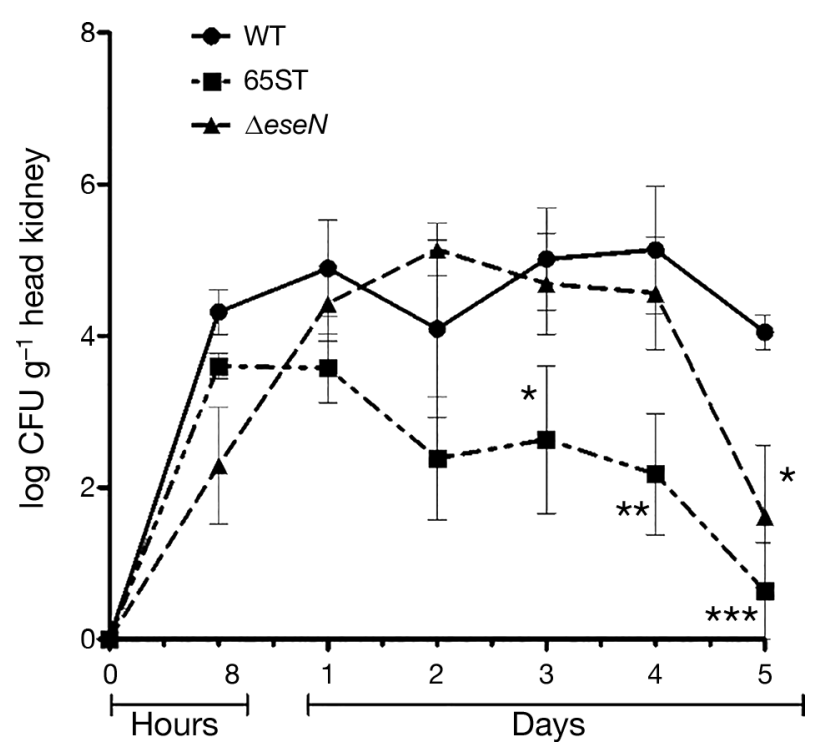

Fig. 8. Persistence of Edwardsiella ictaluri strains in the channel catfish head kidney following a 30 min immersion challenge with either wild-type E. ictaluri (WT), a type III secretion system knockout mutant (65ST), or an eseN mutant $(\Delta e s e N)$. Data are reported as colony forming units (CFU) per gram of head kidney and are presented as the mean \pm SD of quadruplicate samples per group. Data were analyzed by 2-way ANOVA followed by Bonferroni's post hoc test to determine significance of the data for the mutant compared to the WT $\left({ }^{*} \mathrm{p}<0.05,{ }^{* *} \mathrm{p}<0.01,{ }^{* * *} \mathrm{p}<0.001\right)$

pletely avirulent (Thune et al. 2007), again indicating that other T3SS effectors are involved in E. ictaluri virulence.

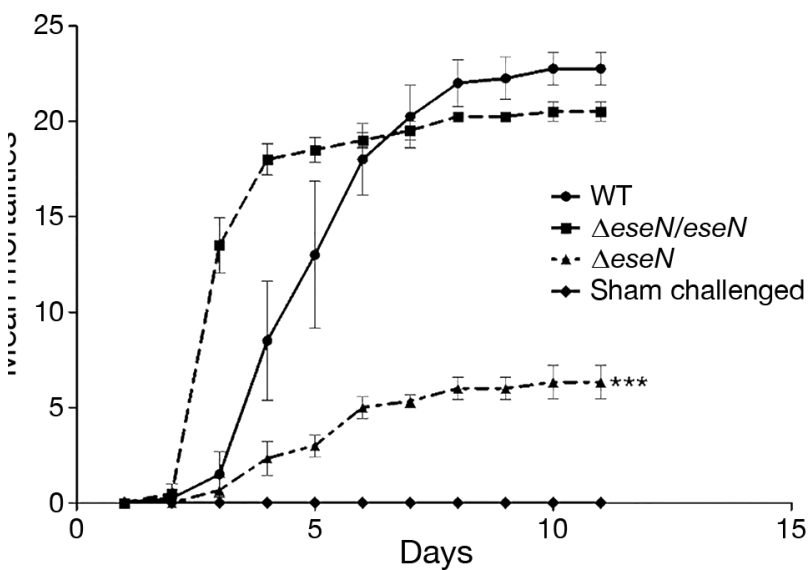

Fig. 9. Role of EseN in virulence. Mortality of channel catfish following a $1 \mathrm{~h}$ immersion challenge with wild-type Edwardsiella ictaluri (WT), eseN mutant ( $\Delta e s e N)$, and complemented $\Delta \operatorname{ese} N(\Delta e s e N / e s e N)$. Comparisons between quadruplicate tanks of $25{\text { fish } \text { tank }^{-1} \text { treatment }}^{-1}$ were based on 1-way ANOVA with Tukey's post hoc test for pairwise comparisons. Mean \pm SD $\left({ }^{* * *} p<0.001\right)$

\section{DISCUSSION}

The PTL domain and the MAPK docking motif of EseN suggest a role in MAPK signaling pathways. However, the $\mathrm{Y} 2 \mathrm{H}$ assay failed to identify a MAPK as a target protein, although the inactivation of pERK1/2 to ERK1/2 by EseN indicated an interaction, which was confirmed by PLA. On the other hand, MVP showed strong interaction with EseN based on activ- 
ity with all of the $\mathrm{Y} 2 \mathrm{H}$ reporter genes, including a very strong reaction in the $\beta$-gal quantitative assay. The failure of pDest22-MVP to induce reporter gene activity when transformed with the empty pDest32 or pDest32 carrying non-specific DNA demonstrated that there was little or no background expression. The strong PLA reaction confirmed the interaction of MVP and EseN. The MVP is the predominant component of the largest ribonucleoprotein particle, named the vault complex, present in eukaryotic cells. The vault complex is associated with many different functions, including multidrug resistance (Sasaki et al. 2002), nuclear-cytoplasmic transport (Liang et al. 2010), innate immunity (Berger et al. 2009), autophagy (Dortet et al. 2012), signal transduction pathways (Berger et al. 2009, Liang et al. 2010), and induction of type I interferon production following hepatitis C virus infection (Liu et al. 2012).

The association of MVP with bacterial pathogens also exhibits different functions depending on the pathogen. For example, in the cytoplasm of infected cells, MVP is able to cover the surface of Listeria monocytogenes by binding to the bacterial surface protein internalin, InlK, which allows this pathogen to escape autophagy recognition (Dortet et al. 2012). The lack of co-localization of MVP with the surface of Edwardsiella ictaluri reported here suggests that MVP plays a different role in an E. ictaluri infection. Recent publications indicate that MVP may serve as a signaling scaffold for ERK1/2 or in the transport of pERK1/2 to the nucleus (Kolli et al. 2004, Liang et al. 2010). Scaffold proteins are important activity regulators of MAPKs that organize and facilitate MAPK signaling pathways through integration or sequestering of proteins, providing a positive or negative regulation role (Zhang \& Dong 2005). The association of EseN with both MVP and ERK1/2 suggests that MVP serves as a scaffolding protein for the interaction of EseN and ERK1/2.

The E. ictaluri T3SS effector EseN belongs to a family of effector proteins encoding a PTL domain. The most studied are OspF in Shigella spp. and SpvC in Salmonella spp., which have 63 and $71 \%$ AA identity to EseN, respectively. The Shigella spp. T3SS effector OspF functions in the nucleus to dephosphorylate the MAPKs pERK1/2 and p38 (Arbibe et al. 2007, Kramer et al. 2007), preventing histone H3 phosphorylation and blocking chromatin accessibility to transcription factor NF- $\kappa \beta$. This results in blockage of a subset of NF- $\kappa \beta$ responsive genes and significantly attenuates recruitment of neutrophils to tissues in mouse and rabbit models compared to a $\Delta o s p F$ mutant (Ausubel 2005). Infection with a $\Delta o s p F$ mutant results in a more aggressive inflammatory response and a markedly stronger neutrophil infiltration in mouse lungs than the WT (Arbibe et al. 2007, Kramer et al. 2007). A $\Delta o s p F$ mutant, however, was no different from the WT relative to the level of conjunctivitis and inflammation in the guinea pig eye model of infection (Zurawski et al. 2009). In addition, infection of polarized T84 intestinal cells with an OspF mutant resulted in reduced phosphorylation of ERK1/2 compared to the WT, as well as reduced neutrophil trans-epithelial migration (Zurawski et al. 2009). These data suggest a differential role for OspF in the intestinal and ocular environments compared to initial invasion of the tissues. In the persistence study for EseN, the $\Delta e s e N$ mutant numbers were lower than the WT after $8 \mathrm{~h}$, suggesting lower initial uptake, but an assay to directly measure trans-epithelial migration is not available for catfish.

The Salmonella T3SS effector SpvC can be delivered to the host cell cytoplasm by both the SPI-1 and SPI-2 encoded T3SS, and inactivates pERK1/2, p38, and JNK (Smith et al. 2009, Neumann et al. 2014). Dephosphorylation of pERK1/2 in the intestinal epithelium, however, is dependent on the SPI-1 T3SS (Haneda et al. 2012). In a mouse infection model, a $\Delta s p v C$ mutant induced pronounced enterocolitis compared to the WT strain $1 \mathrm{~d}$ post-infection. The SpvC WT infection was characterized by reduced transcription of pro-inflammatory cytokines and chemokines, resulting in a reduction in inflammatory-associated pathology compared to the $\Delta s p v C$ mutant. This downregulation of the intestinal inflammatory response by $\mathrm{SpvC}$ resulted in increased systemic spread of Salmonella to the spleen (Haneda et al. 2012). Thus, SpvC exerts anti-inflammatory activity, and attenuation of the intestinal inflammatory response facilitates the systemic spread of the bacterium.

While EseN is clearly a PTL, it is probable that its substrate specificity and/or physiological effects differ from OspF and SpvC. The proteins share only 63 and $71 \%$ AA identity with EseN, and this could allow differential specificity towards MAPKs as well as interaction with different substrates. Differences in timing of translocation and cellular localization following transfection further suggest differential activity. Translocation of OspF occurs from the extracellular environment, through the cytoplasmic membrane, with final location in both the cytoplasm and the nucleus (Zurawski et al. 2009). SpvC is also translocated through the cytoplasmic membrane by the SPI1 T3SS, but localizes only to the cytoplasm (Mazurkiewicz et al. 2008). As reported previously, EseN is translocated from the ECV to the cytoplasm by the 
SPI-2-like T3SS of E. ictaluri (Rogge \& Thune 2011, Baumgartner et al. 2014, Dubytska et al. 2016) and, as demonstrated here, also localizes to the cytoplasm. These differences suggest activation of different pattern recognition receptors, possible dephosphorylation of different MAPKs, and differential activity in the host cell based on the cellular localization.

In summary, E. ictaluri activates ERK1/2 in a manner that is not dependent on EseN early during infection, which would lead to transcriptional reprogramming and induction of an innate immune response (Ausubel 2005, Arbibe et al. 2007, Bhavsar et al. 2007, Diacovich \& Gorvel 2010). Subsequent dephosphorylation of pERK1/2 by the PTL activity of EseN, however, results in production of inactive ERK1/2, which presumably downregulates the host inflammatory response and enhances proliferation of E. ictaluri. This is further suggested by the reduction in tissue numbers of $E$. ictaluri following infection with the $\Delta$ eseN strain compared to the WT, as well as by the resulting reduction in mortality. We further demonstrated that EseN interacts with MVP, possibly as a scaffold protein in support of pERK1/2 dephosphorylation activity. Importantly, EseN is required for efficient replication in the catfish head kidney and for maximum virulence in the catfish host.

Acknowledgements. The work was supported by Agriculture and Food Research Initiative competitive grant no. 2013-67015-21265 from the USDA National Institute of Food and Agriculture. We thank Ms. Sue Hagius from the LSU AgCenter for help with antibody preparation.

\section{LITERATURE CITED}

Agbor TA, McCormick BA (2011) Salmonella effectors: important players modulating host cell function during infection. Cell Microbiol 13:1858-1869

Arbibe L, Kim DW, Batsche E, Pedron T and others (2007) An injected bacterial effector targets chromatin access for transcription factor NF- $\mathrm{KB}$ to alter transcription of host genes involved in immune responses. Nat Immunol 8:47-56

Arthur JS, Ley SC (2013) Mitogen-activated protein kinases in innate immunity. Nat Rev Immunol 13:679-692

Ausubel FM (2005) Are innate immune signaling pathways in plants and animals conserved? Nat Immunol 6:973-979

*Baumgartner WA, Dubytska L, Rogge ML, Mottram PJ, Thune RL (2014) Modulation of vacuolar $\mathrm{pH}$ is required for replication of Edwardsiella ictaluri in channel catfish macrophages. Infect Immun 82:2329-2336

Berger W, Steiner E, Grusch M, Elbling L, Micksche M (2009) Vaults and the major vault protein: novel roles in signal pathway regulation and immunity. Cell Mol Life Sci 66:43-61

Bhavsar AP, Guttman JA, Finlay BB (2007) Manipulation of host-cell pathways by bacterial pathogens. Nature 449: 827-834
Booth NJ, Elkamel A, Thune RL (2006) Intracellular replication of Edwardsiella ictaluri in channel catfish macrophages. J Aquat Anim Health 18:101-108

Coburn B, Sekirov I, Finlay BB (2007) Type III secretion systems and disease. Clin Microbiol Rev 20:535-549

Cornelis GR, Van Gijsegem F (2000) Assembly and function of type III secretory systems. Annu Rev Microbiol 54: $735-774$

*Dean P (2011) Functional domains and motifs of bacterial type III effector proteins and their roles in infection. FEMS Microbiol Rev 35:1100-1125

* Diacovich L, Gorvel JP (2010) Bacterial manipulation of innate immunity to promote infection. Nat Rev Microbiol 8:117-128

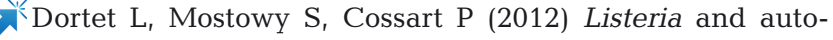
phagy escape: involvement of InlK, an internalin-like protein. Autophagy 8:132-134

* Dubytska LP, Rogge ML, Thune RL (2016) Identification and characterization of putative translocated effector proteins of the Edwardsiella ictaluri Type III secretion system. MSphere 1:e00039-16

* Figueira R, Holden DW (2012) Functions of the Salmonella pathogenicity island 2 (SPI-2) type III secretion system effectors. Microbiology 158:1147-1161

Galán JE, Wolf-Watz H (2006) Protein delivery into eukaryotic cells by type III secretion machines. Nature 444: $567-573$

* Haneda T, Ishii Y, Shimizu H, Ohshima K, Iida N, Danbara H, Okada N (2012) Salmonella type III effector SpvC, a phosphothreonine lyase, contributes to reduction in inflammatory response during intestinal phase of infection. Cell Microbiol 14:485-499

* He QZ, Zeng HC, Huang Y, Hu YQ, Wu YM (2015) The type III secretion system (T3SS) of Chlamydophila psittaci is involved in the host inflammatory response by activating the JNK/ERK signaling pathway. BioMed Res Int 2015: 652416

Isaac J, Fries LT (1991) Separation of channel catfish eggs in sodium sulfate with and without papain. Prog Fish-Cult 53:200-201

Kaur J, Jain SK (2012) Role of antigens and virulence factors of Salmonella enterica serovar Typhi in its pathogenesis. Microbiol Res 167:199-210

Kim DW, Chu H, Joo DH, Jang MS and others (2008) OspF directly attenuates the activity of extracellular signal-regulated kinase during invasion by Shigella flexneri in human dendritic cells. Mol Immunol 45: 3295-3301

Kline T, Felise HB, Sanowar S, Miller SI (2012) The type III secretion system as a source of novel antibacterial drug targets. Curr Drug Targets 13:338-351

Kolli S, Zito CI, Mossink MH, Wiemer EA, Bennett AM (2004) The major vault protein is a novel substrate for the tyrosine phosphatase SHP-2 and scaffold protein in epidermal growth factor signaling. J Biol Chem 279: 29374-29385

Kovach ME, Elzer PH, Hill DS, Robertson GT, Farris MA, Roop RM II, Peterson KM (1995) Four new derivatives of the broad-host-range cloning vector pBBR1MCS, carrying different antibiotic-resistance cassettes. Gene 166: 175-176

Kramer RW, Slagowski NL, Eze NA, Giddings KS and others (2007) Yeast functional genomic screens lead to identification of a role for a bacterial effector in innate immunity regulation. PLOS Pathog 3:e21 
Krzyzowska M, Swiatek W, Fijalkowska B, Niemialtowski M, Schollenberger A (2010) The role of MAP kinases in immune response. Adv Cell Biol 2:125-138

Lawrence T (2009) The nuclear factor NF- $\kappa B$ pathway in inflammation. Cold Spring Harb Perspect Biol 1:a001651

Li H, Xu H, Zhou Y, Zhang J and others (2007) The phosphothreonine lyase activity of a bacterial type III effector family. Science 315:1000-1003

Liang P, Wan Y, Yan Y, Wang Y and others (2010) MVP interacts with YPEL4 and inhibits YPEL4-mediated activities of the ERK signal pathway. Biochem Cell Biol 88: 445-450

Liu S, Hao Q, Peng N, Yue X and others (2012) Major vault protein: a virus-induced host factor against viral replication through the induction of type-I interferon. Hepatology 56:57-66

Marteyn B, Gazi A, Sansonetti P (2012) Shigella: a model of virulence regulation in vivo. Gut Microbes 3:104-120

Mazurkiewicz P, Thomas J, Thompson JA, Liu M, Arbibe L, Sansonetti P, Holden DW (2008) SpvC is a Salmonella effector with phosphothreonine lyase activity on host mitogen-activated protein kinases. Mol Microbiol 67: 1371-1383

Miao EA, Brittnacher M, Haraga A, Jeng RL, Welch MD, Miller SI (2003) Salmonella effectors translocated across the vacuolar membrane interact with the actin cytoskeleton. Mol Microbiol 48:401-415

Neumann C, Fraiture M, Hernandez-Reyes C, Akum FN and others (2014) The Salmonella effector protein SpvC, a phosphothreonine lyase is functional in plant cells. Front Microbiol 5:548

Rogge ML, Thune RL (2011) Regulation of the Edwardsiella ictaluri type III secretion system by $\mathrm{pH}$ and phosphate concentration through EsrA, EsrB, and EsrC. Appl Environ Microbiol 77:4293-4302

Editorial responsibility: Andrew Barnes, Brisbane, Queensland, Australia
Sasaki T, Hankins GR, Helm GA (2002) Major vault protein/ lung resistance-related protein (MVP/LRP) expression in nervous system tumors. Brain Tumor Pathol 19:59-62

Skaug B, Jiang X, Chen ZJ (2009) The role of ubiquitin in NF- $\kappa \mathrm{B}$ regulatory pathways. Annu Rev Biochem 78: 769-796

* Smith GK, Ke Z, Hengge AC, Xu D, Xie D, Guo H (2009) Active-site dynamics of SpvC virulence factor from Salmonella typhimurium and density functional theory study of phosphothreonine lyase catalysis. J Phys Chem B 113:15327-15333

* Thune RL, Fernandez DH, Benoit JL, Kelly-Smith M and others (2007) Signature-tagged mutagenesis of Edwardsiella ictaluri identifies virulence-related genes, including a Salmonella pathogenicity island 2 class of type III secretion systems. Appl Environ Microbiol 73:7934-7946

Wall DM, McCormick BA (2014) Bacterial secreted effectors and caspase-3 interactions. Cell Microbiol 16:1746-1756

Zhang YL, Dong C (2005) MAP kinases in immune responses. Cell Mol Immunol 2:20-27

Z Zhang Y, Deng Q, Porath JA, Williams CL, Pederson-Gulrud KJ, Barbieri JT (2007) Plasma membrane localization affects the RhoGAP specificity of Pseudomonas ExoS. Cell Microbiol 9:2192-2201

* Zhu J, Mohan C (2010) Toll-like receptor signaling pathways - therapeutic opportunities. Mediators Inflamm 2010:781235

K Zhu Y, Li H, Long C, Hu L and others (2007) Structural insights into the enzymatic mechanism of the pathogenic MAPK phosphothreonine lyase. Mol Cell 28:899-913

Kurawski DV, Mumy KL, Faherty CS, McCormick BA, Maurelli AT (2009) Shigella flexneri type III secretion system effectors OspB and OspF target the nucleus to downregulate the host inflammatory response via interactions with retinoblastoma protein. Mol Microbiol 71:350-368

Submitted: March 1, 2018; Accepted: June 1, 2018

Proofs received from author(s): August 16, 2018 